\title{
Inhaltsverzeichnis
}

Einleitung -1

\section{Theoretische Bestimmungen}

Thomas Böhm

Facetten eines Theoria-Entwurfes in der Spätantike - 15

Günter Figal

Die Räumlichkeit der Muße -26

Hans-Georg Soeffner

Muße - Absichtsvolle Absichtslosigkeit — 34

Gregor Dobler

Muße und Arbeit -54

Peter Strohschneider

Muße und Wissenschaft. Ein Gespräch mit Burkhard Hasebrink und Peter Philipp Riedl -69

\section{Literarische Konfigurationen}

Wolfgang Kofler

Muße in der römischen Literatur. Zwei Inszenierungen

in Ennius' Iphigenie und Plinius' Epistel 1.6 — 91

Burkhard Hasebrink

Zwischen Skandalisierung und Auratisierung.

Über gemach und muoze in höfischer Epik — 107

Almut Suerbaum

,A Room with a view'. Zur Spannung zwischen Kontemplation und Leben in der Welt in den Dorotheenviten des Johannes Marienwerder 
Kerstin Fest

„Bless me, papa, what a strange place this is". Muße und

Professionalität im englischen Metadrama des 18. Jahrhunderts - 152

Dieter Martin

Muße, Autonomie und Kreativität in der deutschen Dichtung

des 18. Jahrhunderts -167

Peter Philipp Riedl

Entschleunigte Moderne. Muße und Kunsthandwerk in

der Literatur um 1900 - 180

\section{Kulturelle Formationen}

Alexander Heising

Otium in den Provinzen? Archäologische Nachweismöglichkeiten

potentieller Mußeräume in der gallorömischen Villenkultur — 219

Gabriele Seitz

Otium am Oberrhein? Ein Plädoyer 238

Katharina Krause

Drinnen und draußen. Wüste und Garten als Orte der Muße

im Frankreich des 17. Jahrhunderts -260

Christophe Granger

Children of the Otium. How the French got Leisured (since 1900) 279

Wolfgang Kubin

Muße und Melancholie - eine nicht nur chinesische Sicht — 304 